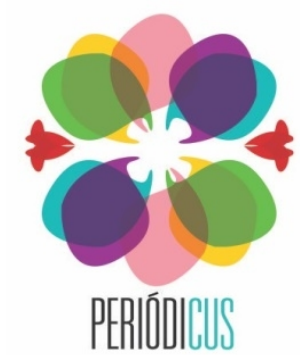

ISSN: 2358-0844

n. 16, v. 2

set.2021-dez.2021

p. $81-92$

\title{
O abuso sexual infantil
} e a cultura do silêncio: machismo, racismo e adultocentrismo em questão

(Child sexual abuse and silence culture: discussions on sexism, racism and adultcentrism)

(El abuso sexual infantil y la cultura del silencio: machismo, racismo y adultocentrismo en cuestión)

\author{
Wilmar Ferreira Neves Neto ${ }^{1}$ \\ Marília Gabriela Costa Rezende ${ }^{2}$ \\ Cíntia De Sousa Carvalho ${ }^{3}$
}

RESUMO: A ideia de proteção à infância, sobretudo quanto às violências sexuais, é uma construção social recente e o enfrentamento desse fenômeno é um desafio na contemporaneidade. Por outro lado, ainda existe uma resistência em compreender crianças como sujeitos de direitos e, por isso, há uma má interpretação dos seus respectivos direitos sexuais. Percebemos assim que, visando garantir a proteção, muitos dos direitos de crianças são violados. Buscamos então, com essa revisão bibliográfica, aprofundar o conceito de abuso sexual infantil numa perspectiva de gênero, além de enfatizar as implicações dos atravessamentos de uma cultura machista, racista e adultocêntrica na relação abusiva, bem como no seu silenciamento.

PALAVRAS-CHAVE: Abuso sexual infantil. Violência de gênero. Adultocentrismo.

\begin{abstract}
The idea of child protection, especially regarding sexual violence, is a recent social construction and combating this phenomenon is a challenge in contemporary times. On the other hand, society remains resistant in understanding children as subjects of rights, which results in a misinterpretation of their respective sexual rights. We thus observe that, in order to ensure protection, many children's rights are violated. This literature review seeks to propose a more in-depth concept of child sexual abuse based on gender, and emphasize the impacts a sexist, racist, and adult-centered culture in the abusive relationship, as well as its silencing.

Keywords: Child sexual abuse. Gender-based violence. Adultcentrism.
\end{abstract}

Resumen: La idea de la protección infantil, especialmente con respecto a la violencia sexual, es una construcción social reciente, y la confrontación de este fenómeno es un desafío en los tiempos contemporáneos. Por otro lado, todavía hay resistencia para entender a los niños como sujetos de derechos y, por lo tanto, hay una mala interpretación de sus

1 Acadêmico do curso de Psicologia do Centro Universitário de Mineiros - UNIFIMES. E-mail: wilmar2012_@outlook.com.

2 Acadêmica do curso de Psicologia do Centro Universitário de Mineiros - UNIFIMES. E-mail: marygabi015@gmail.com.

3 Profa. Dra. Efetiva do curso de Psicologia do Centro Universitário de Mineiros - UNIFIMES. E-mail: psi.cintiacarvalho@gmail.com. 
respectivos derechos sexuales. Por lo tanto, para garantizar la protección se violan los derechos de muchos niños. Con esta revisión de la literatura, buscamos profundizar en el concepto de abuso sexual infantil desde una perspectiva de género y enfatizar las implicaciones de los cruces de una cultura machista, racista y centrada en el adulto en la relación abusiva, así como su silencio.

Palabras clave: Abuso sexual infantil. Violencia de género. Adultocentrismo. 


\section{Introdução}

O abuso sexual infantil é um tipo de violência que passou a ser considerada como uma situação de violação de direitos em tempos recentes, mais especificamente, com a Lei $n^{\circ}$ 8.069, que institui o Estatuto da Criança e do Adolescente. (BRASIL, 1990) No entanto, algumas práticas sempre existiram na história da humanidade, ainda que os sentidos e as gramáticas sociais ao redor dessas práticas fossem alterando modos de ver e interpretar a realidade, o que suscitou as mudanças em relação ao que definimos, ou não, como violência. As transformações econômicas alteraram os jogos de poder, transmutando a violência em um dispositivo de controle dos corpos. Assim, é importante considerar como as questões do machismo, do heterossexismo e do adultocentrismo fomentaram e fomentam atitudes violentas de controle da sexualidade e que culminam em práticas como o abuso sexual.

De modo geral, a literatura aponta para dados que convergem acerca do abuso sexual infantil no Brasil, afirmando a sua predominância no ambiente intrafamiliar, em que o agressor é, na maioria das vezes, o pai ou padrasto da criança, e as vítimas geralmente são do sexo feminino, bem como com menor grau de escolarização. (BAPTISTA et al., 2008; SERAFIM et al., 2011) Entretanto, há de se considerar um processo de silenciamento social que dificulta a coleta de dados concretos sobre esse tipo de violência, provocando a subnotificação de grande parte dos casos de abuso contra crianças.

Uma experiência violenta quando ocorre, principalmente, na primeira infância, pode acarretar sérios prejuízos para o desenvolvimento da criança. Serafim et al. (2011) apontam para a depressão como o transtorno que mais acomete pessoas vítimas de abuso sexual infantil. Tendo em vista que esse tipo de violência é um fenômeno social que fere os direitos humanos e provoca sérios danos para a saúde física e mental das vítimas é importante debater, no âmbito social, formas de preveni-lo, mas também, na esfera pós-violência, refletir acerca das práticas profissionais na rede de acolhimento das vítimas e a situação da revitimização por parte desses profissionais.

Dessa forma, o presente texto, fruto de uma ampla revisão bibliográfica realizada a partir do projeto de pesquisa denominado Experiências sexuais violentas na infância: o panorama do abuso sexual em Mineiros/GO, tem como objetivo aprofundar o conceito de abuso sexual infantil numa perspectiva dos direitos sexuais infantis, problematizando o silenciamento da discussão sobre esse tema na sociedade em geral. Esse trabalho se justifica, pois, os casos de abuso continuam crescendo. Cerca de 17.093 denúncias de violência sexual foram registradas no ano de 2018 pelo Disque 100. (BRASIL, 2019) Assim, mais do que quantificar os dados das 
violações, faz-se necessário compreender as engrenagens que sustentam e pulverizam essa realidade.

\section{Dados sobre o abuso sexual infantil: traçando um perfil dos envolvidos}

O abuso sexual infantil é um tipo de violência sexual proveniente de uma relação assimétrica de poder entre dois indivíduos de idades distintas e que ocorre quando sua relação de autoridade é extrapolada em função da satisfação sexual unicamente do agressor. (BAPTISTA et al., 2008; CONSELHO FEDERAL DE PSICOLOGIA, 2009) De acordo com Felipe (2006) o termo abuso é problemático, visto que induz apenas à ideia de excesso. Entretanto, a violência sexual infantil não é apenas um transbordamento, mas uma transgressão física e simbólica socialmente inaceitável, pois objetifica o corpo infantil.

Há muitas pesquisas que apontam dados quanto à incidência do abuso sexual infantil, mas destacamos o estudo de Baptista et al. (2008) que identificaram o perfil das vítimas no município de Campina Grande, na Paraíba. Segundo o autor, as principais vítimas são meninas, de idades entre 12 e 14 anos, com ensino fundamental incompleto e baixo nível socioeconômico. Entretanto, na interpretação desses dados, é importante compreender que o adolescente tem maior poder social para revelar um caso de abuso, bem como maior capacidade de entendimento para saber identificar a situação como violenta. Isso significa que a criança possui menos condições de revelação e menor capacidade de discernir acerca da violência. Assim, os resultados da investigação de Baptista et al. (2008) devem ser interpretados a partir desses limites. Além disso, nas classes sociais mais favorecidas há uma facilidade e maior interesse em abafar esse tipo de caso que tanto repercute no convívio social, principalmente quando o abusador é alguém de dentro da família da vítima, o que nos aponta para um processo de silenciamento nas classes sociais economicamente privilegiadas.

Crianças tendem a ser alvo mais fácil da violência sexual por estarem em fase de desenvolvimento. O abusador aproveita da hierarquia de idade e maturidade para seduzir e convencer a vítima a ocultar a relação que se estabelece entre eles. Sua vulnerabilidade se torna ainda maior por conta de questões biológicas, cognitivas e por fatores sociais como o adultocentrismo, que enfraquecem a visão da criança como sujeito de direitos, tornando seu discurso menos legítimo. (CARVALHO et al., 2012; SANTOS; DELL’AGLIO, 2010)

Como dito anteriormente, o abuso sexual assume diferentes formas de manifestação, mas a característica principal é a utilização do corpo da vítima como um objeto capaz de despertar o gozo de quem a deseja numa relação unilateral. O abusador, segundo Neves (2010), geralmente é um membro da própria família da vítima, sendo esse caso considerado uma relação incestuosa. 
Por outro lado, em alguns casos, ele pode pertencer a um ambiente extrafamiliar: escola, igreja, bairro, entre outros.

Saffioti (1997) e Felipe (2006), analisando essa maior incidência do abuso intrafamiliar, asseveram que o abusador, diferente do que supostamente povoa o imaginário social, é um sujeito acima de qualquer suspeita: casado, maior de 35 anos, sem antecedentes criminais, grau de parentesco próximo (pai, tio ou avô) e nível econômico médio ou alto. Vemos, portanto, que o lugar de proteção, na situação do abuso sexual, a saber, o seio familiar, torna-se um espaço que vulnerabiliza as crianças. Entende-se que a família deveria ser a primeira a cumprir com a responsabilidade na promoção dos direitos fundamentais das crianças e adolescentes, tendo em vista que essa instituição constitui o primeiro campo de socialização do sujeito, sendo ainda um dos mais importantes. Ao menos é o que preconiza a Lei n 8.069, de 13 de julho de 1990:

Art. 4. É dever da família, da comunidade, da sociedade em geral e do poder público assegurar, com absoluta prioridade, a efetivação dos direitos referentes à vida, à saúde, à alimentação, à educação, ao lazer, à profissionalização, à cultura, à dignidade, ao respeito, à liberdade e à convivência familiar e comunitária. (BRASIL, 1990)

Frente a essa problemática, foi somente após os anos 1980, concomitante a um processo de redemocratização do país, que surgiram programas com o foco no combate ao abuso sexual infantil. (NEVES et al., 2010) O Estatuto da Criança e do Adolescente concretizou o artigo 227 da Constituição Federal, determinando direitos e garantias fundamentais da criança e adolescente, tendo como compromisso a sua proteção integral. Por sua data de promulgação, é possível perceber que a inclusão dessa parcela da população como sujeito de direitos é bem recente. Até o século XX não existia sequer a especificação de “infância” e "adolescência” como fases do desenvolvimento humano. Segundo Ariès (1978), não havia tentativa de representar a infância na arte medieval, as crianças eram ilustradas como miniaturas dos adultos. Somente a partir do século XIII uma diferenciação entre infância e idade adulta começou a ser estabelecida, mas a adolescência somente foi reconhecida em meados do século XIX e início do século XX.

Assim, falar de direitos sexuais, direitos que devem zelar pela integridade física e moral das crianças e adolescentes no campo do exercício de sua sexualidade e na prevenção contra a prática do abuso sexual, torna-se uma importante tarefa para desmistificar as representações sociais que definem essa esfera da vida. Tendo ganhado força a partir da Conferência de Cairo em 1994, como parte dos direitos humanos, os direitos sexuais e reprodutivos passaram a ser incluídos na agenda política de diversos países, assumindo a sexualidade como uma dimensão humana. (CARVALHO et al., 2012) Entretanto, apesar dos avanços legais, tal discussão ainda se faz necessária em virtude das barreiras impostas por uma moral conservadora e que ameaçam a luta por esses direitos mal interpretados socialmente. 
De acordo com Carvalho et al. (2012) há uma incompreensão social acerca da ideia dos direitos sexuais e reprodutivos, tomando-os meramente como formas de combate à violação sexual e à gravidez precoce, isto é, partindo unicamente de uma perspectiva da prevenção de riscos e não da garantia de direitos. Esse viés reflete um certo protecionismo das instituições sobre a criança, ideário que a percebe como um sujeito incapaz e inocente, e que deve ser protegido para o futuro da nação. Contudo, para os autores, esse modo de interpretar os direitos sexuais pode retirar a capacidade de autonomia do indivíduo frente ao exercício da sua sexualidade. É preciso garantir-lhe o acesso ao conhecimento e a liberdade de manipular as informações de diversas formas sem lhes privar, no entanto, de orientação.

Por estar relacionado à agressão de pessoas menores de idade, o abuso sexual infantil poderia ser compreendido como uma prática de pedofilia. Esta, legalmente, não é tipificada como crime, mas é considerada uma doença pela Organização Mundial da Saúde (OMS) e representada na Classificação Internacional das Doenças (CID) como transtorno da preferência sexual indicado pelo F65.4. (ORGANIZAÇÃO MUNDIAL DA SAÚDE, 1997) Entretanto, de acordo com Felipe (2006), poucos são os casos de abuso em que os envolvidos são pedófilos. Como dito anteriormente, o perfil dos abusadores nos aponta indivíduos acima de qualquer suspeita.

A própria noção de pedofilia deve ser contemporaneizada. Ou seja, até o século passado ainda era uma prática comum, por exemplo, que as famílias entregassem suas filhas logo que elas atingissem a puberdade a homens mais velhos em casamentos arranjados, o que hoje seria considerado incitação à pedofilia. Em outras culturas contemporâneas, em que as crianças não passam por um período de escolarização intenso, como na cultura bambara, elas buscam experienciar seus conhecimentos sexuais logo cedo, sem passar pelo período de latência como o conhecemos. (NATHAN, 1997) Mas, recentemente, na maioria das sociedades ocidentais, o costume de aceitar o exercício da sexualidade infantil tornou-se um problema, no maior parte das vezes, um crime. Em contrapartida, é legalizada e incentivada uma exacerbada sexualização e valorização do corpo infantojuvenil pela mídia, o que contribui para o aumento do número de violências sexuais e adolescentes grávidas. (FELIPE, 2006)

\section{0 abuso sexual como uma violência de gênero}

A espécie humana consegue ser diferente de todos os outros seres vivos, por ser capaz de fazer o uso da razão, pensando e interagindo com a natureza de uma forma totalmente exclusiva. Para Saffioti (1997), a partir dessa interatividade com o ambiente, atribuímos significados para as nossas próprias ações, às dos outros, aos objetos e fatos, em um processo de simbolização. O 
homem possui o poder de simbolizar, conseguindo criar a cultura, um elemento ausente nas sociedades animais, bem como uma série de hierarquizações, denominadas por Saffioti (1997) como "gramáticas”, conjunto de regras que são socializadas na esfera social, regulando as relações humanas.

Ainda segundo a autora acima citada, tais gramáticas são ensinadas desde cedo pela família para que os filhos aprendam a desempenhar seus papéis sociais em meio ao afeto ou repreensão. Saffioti (1997) entende que responsável por regular as relações entre homem e mulher, temos a gramática sexual ou de gênero. Para inferiorizar ou enaltecer uma pessoa pela sua raça, temos a gramática de raça/etnia. Dividindo os indivíduos entre pobres e ricos, visando a dominação/exploração de uma determinada classe, temos a gramática de classe social. A autora aponta ainda uma outra gramática, secundária, que regula as relações humanas conforme a idade. Essa divisão etária produz uma hierarquia em que o adulto tem maior poder de decisão sobre a criança, o adolescente e o idoso. Assim, tomando a organização social por meio da interação entre as gramáticas de regulação social, Saffioti (1997) conclui que a menina negra estaria no grau mais elevado de vulnerabilidade social, por ser a última nessa escala de poder. Assim, são as crianças do sexo feminino, negras e economicamente desfavorecidas que lideram o ranking das violações sexuais. Vemos, portanto, como o machismo, o racismo, a desigualdade social e o adultocentrismo sustentam as violências sexuais, dando-lhe um determinado corpo. $\mathrm{O}$ abuso sexual está perpassado por esses fenômenos, sendo impossível desassociá-lo desse repertório.

Tendo em vista os dados apresentados no tópico anterior sobre o abuso sexual infantil como uma violência de gênero, a enorme discrepância entre a violação de meninos e meninas evidencia a intensa participação do patriarcalismo na (re)produção das violências sexuais. Isso também é demonstrado em uma pesquisa feita por Serafim et al. (2011), em que os autores investigaram a visão sobre as figuras do masculino e do feminino por crianças vítimas de abuso. Foi observado que a mulher é considerada como fraca e incapaz, e o homem como naturalmente forte e agressivo, dotado de um instinto incontrolável. Isso demonstra como o abuso se torna um instrumento da violência de gênero, perpetuando-a. (SCHREINER, 2008)

Ao realizar um trabalho com meninas abusadas sexualmente por incesto, Schreiner (2008) identificou durante a sua convivência com as vítimas que havia entre as famílias e a sociedade um processo de atribuição da responsabilidade às meninas. A interação abusiva praticada pelo agressor, geralmente é antecedida por uma aproximação sedutora e induz a criança a interpretá-la como uma forma de dar afeto e carinho. O suposto carinho recebido mantém por bastante tempo o abusador em segredo, até que a vítima tenha maturidade para reconhecer a reprovação social do ato e seus efeitos nocivos. Conforme a revelação demore a acontecer e a 
manifestação de carinho e afeto pelo abusador se prolongue, ao olhar de muitos adultos a menina é corresponsável pela sua experiência abusiva. Uma vez mais, a vítima torna-se culpada.

Quando finalmente o abuso é revelado, ainda existe entre os pais uma pressão para a negação do fato, principalmente por parte da mãe. A menina, mesmo após superar as barreiras da revelação, ainda é submetida à acusação de que é responsável pela instabilidade ou ruína familiar, pelo rompimento dos laços familiares, pela prisão eventual do abusador, pelas dificuldades financeiras e outras. O uso de roupas curtas e a fama de “namoradeiras” são também equivocadamente referidos como comportamentos sexualizados que justificam as respostas abusivas, responsabilizando a menina pelo abuso sofrido. (SCHREINER, 2008)

Percebe-se que as relações de poder e gênero arbitrárias e os tabus frente ao abuso sexual criam contexto para uma série de atitudes e ideias imprudentes por parte dos pais, da família e a sociedade em geral. Segundo Schreiner (2008), a reação do pai e da mãe, a pressão para a negação do fato e a responsabilização da menina, dificultam o reconhecimento do abuso sexual no seu processo de revelação e de enfrentamento, sendo assim uma forma sutil de revitimização da pessoa abusada sexualmente.

Não só os pais adquirem crenças naturalizantes que levam ao silenciamento, mas também discursos políticos mais amplos endossam o caminho do silêncio. Bonfanti e Gomes (2018) apontam que muitos discursos conservadores temem uma suposta "ideologia de gênero" a ser pregada nas escolas, por representar uma ameaça às crianças e à família tradicional brasileira. Assim, entendem que gênero e sexualidade não são temas a serem debatidos na esfera pública, tornando-se a família a única instituição social legítima para apresentar tais questões às crianças.

Entretanto, os autores destacam que a ideologia de gênero nasce da naturalização das diferenças entre os sexos, ou seja, de um discurso biológico que justifica a hierarquia de gênero presente em todas as instituições sociais. Isso implica considerar, por exemplo, que a mulher deve ocupar cargos inferiores porque nasceu para ser mãe e cuidar da casa. Entretanto, mal sabem que por reforçarem diariamente essas diferenciações biológicas, estão eles próprios pregando uma determinada ideologia de gênero. (BONFANTI; GOMES, 2018) Os autores concluem, portanto, que não seria pela via do silêncio que poderíamos combater as violações sexuais, mas pela via do discurso, seja aquele que orienta, seja aquele que revela.

Conforme Saffioti (1997), na cultura machista, o sexo masculino é supervalorizado e considerado superior ao sexo feminino. A partir disso surge a desigualdade de gênero, colocando a mulher em uma posição de inferioridade e submissão. Com isso, vemos no cotidiano mulheres sendo assediadas, relações maritais abusivas mantidas por uma dependência econômica e/ou emocional ou até mesmo mulheres assassinadas simplesmente por serem mulheres. 
Para Schreiner (2008), ao colocarmos homens e mulheres em posições assimétricas de poder na sociedade, criamos então o que a autora chama de “violência de gênero". Nessa perspectiva, o homem, quando pratica o abuso sexual incestuoso, encontra-se rodeado por uma posição vantajosa, em vários sentidos, atribuída à sua figura masculina desde "o chefe da casa” ao detentor da força e disciplina. Dispondo ainda da sua condição de adulto, mais velho, experiente e alguém que tem a confiança da criança ou adolescente, adentra numa relação de superioridade que prevê a obediência dos seus subordinados, inclusive quanto à satisfação de seus desejos sexuais. Enquanto isso,

\begin{abstract}
elementos como a socialização de gênero e a cultura familiar adultocêntrica podem interferir fortemente na tomada de consciência por parte de quem pratica a violência, dificultando a percepção de seu ato como um crime grave. Também uma hierarquia familiar fortemente marcada pelo sexismo e pelo machismo pode facilitar a formação de homens e mulheres abusadores(as). (CONSELHO FEDERAL DE PSICOLOGIA, 2009, p. 42)
\end{abstract}

Bonfanti e Gomes (2018) nos levam a pensar como toda a estrutura social foi construída com base nas gramáticas citadas por Saffioti (1997), sobretudo na hierarquia de gênero, uma forma primária de desigualdade baseada no patriarcalismo. Segundo os autores, nesse sistema social todos são submissos ao patriarca representado em nossa sociedade pelo homem heterossexual, branco e cristão. Da figura dele vão se sucedendo vários outros graus de hierarquias que podem substituí-lo em algum momento. Entretanto, os autores nos mostram que pensar as instituições sociais como locais de reprodução dessa relação de poder nos leva a identificar os seus mecanismos de manutenção a partir da criação de uma verdade universal sobre a sexualidade e que irá justificar a posição que o patriarca ocupa. A partir do estabelecimento de uma normativa, todos os seus desvios passam a ser vistos como uma ameaça e quando eles se tornam visíveis surge a necessidade de discursos conservadores para preservar esse machismo estrutural.

Essas questões nos levam a entender um pouco a dificuldade que tivemos em pesquisar o abuso sexual infantil no município de Mineiros, em Goiânia. Empenhamos esforços durante o ano de 2019 para levantar dados públicos acerca dos números das violências sexuais no município através de instituições públicas. Entretanto, até o momento, a resposta que recebemos foi o silêncio. Mineiros é uma cidade pequena (cerca de 52 mil habitantes), tradicional, de economia agrária, mas que vem sofrendo grandes transformações com o advento de empresas multinacionais nos últimos anos. Nesse aspecto, com o aumento populacional, a chegada de culturas de outras regiões do país e as transformações espaciais, em alguma medida, a cidade parece preservar sua imagem por meio de seu silêncio. Esse fato nos remete a imaginar que, em 
muitos casos, os indivíduos se limitam às suas próprias concepções de verdade para proteger, como diria Saffioti (1997), seus “terreiros simbólicos”.

\section{Considerações finais}

O artigo em questão teve por objetivo aprofundar o conceito de abuso sexual infantil numa perspectiva dos direitos sexuais, problematizando o silenciamento da discussão sobre esse tema na sociedade em geral. Pensar na atuação do psicólogo em contextos de violação dos direitos sexuais na infância é uma tarefa hercúlea e necessária. É preciso lidar com questões polêmicas que afetam a moral da maior parte da população, mas ao mesmo tempo se faz extremamente necessário para a prevenção de danos primários e secundários ao pleno desenvolvimento desses indivíduos. O abuso sexual, quando ocorre nas primeiras fases da vida, pode se transformar em um trauma profundo que irá afetar diretamente a qualidade de vida da vítima.

Serafim et al. (2011) indicam a depressão como o transtorno que mais acomete as pessoas vítimas de abuso sexual infantil. Além disso, Rios (2003) aponta para um possível ciclo de HIV sendo transmitido em práticas sexuais violentas, alertando para infantilização do HIV. Tendo em vista que esse tipo de violência é um fenômeno social que fere os direitos humanos e provoca sérios danos para a saúde mental e física das vítimas, é importante promover a discussão sobre as práticas dos profissionais que atuam na rede destinada ao acolhimento das vítimas de abuso, buscando também incentivar o debate sobre os direitos sexuais e reprodutivos direcionados ao público infantil. As formações profissionais parecem ser uma via potente de transformação da realidade, momento em que as gramáticas de exclusão social sustentadas pelo machismo, pela misoginia e pelo racismo devem ser problematizadas.

Por outro lado, é preciso trabalhar também com os agressores que, em muitos casos, também foram vítimas de violência na infância. Isto é, aquele que viola, muito possivelmente, advém de uma trajetória de violação de direitos.

É importante desenvolver um bom trabalho de prevenção para evitar o ocultamento de informações ou mesmo a subnotificação, devido ao sentimento de medo ou culpa da vítima em relação às consequências da denúncia para a desconstrução da sua família. Por isso, tornam-se importantes os mecanismos de proteção do Estado, que visam a garantia dos direitos humanos a todos os indivíduos por meio da implantação e investimento em políticas públicas. É preciso que o tema seja trabalhado nas escolas, contrariando a ideia de que a família detém o poder sobre o assunto. Por fim, entendemos que seja necessário fomentar o debate sobre os direitos sexuais, 
visando desmistificá-los como um assunto privado à vida adulta, entendendo o direito sexual também como direito à informação, à liberdade e à autonomia.

\section{Referências}

ARIÈS, P. História social da criança e da família. Tradução: Dora Flaksman. 2. ed. Rio de Janeiro: Guanabara, 1986.

BAPTISTA, R. S. et al. Caracterização do abuso sexual em crianças e adolescentes notificado em um Programa Sentinela. Acta Paulista de Enfermagem, São Paulo, v. 21, n. 4, p. 602-608, 2008.

BONFANTI, Ana Letícia; GOMES, Aguinaldo Rodrigues. A quem protegemos quando não falamos de gênero na escola? Periódicus. n. 09, v. 01, 2018.

BRASIL. Lei Federal n ${ }^{0}$ 8.069, de 13 de julho de 1990. Dispõe sobre o Estatuto da Criança e do Adolescente e dá outras providências. Diário Oficial da União, Brasília, DF, 16 jul. 1990.

BRASIL. Ministério da Mulher, da Família e dos Direitos Humanos. Disque Direitos Humanos: Relatório 2019. Brasília, DF: Ministério da Mulher, da Família e dos Direitos Humanos, 2019. Disponível em: https://bit.ly/3eiT12f. Acesso em: 7 dez. 2019.

CARVALHO, C. S. et al. Direitos sexuais de crianças e adolescentes: avanços e entraves. Psicologia Clínica, Rio de Janeiro, v. 24, n. 1, p. 6988, 2012.

CONSELHO FEDERAL DE PSICOLOGIA. Serviço de proteção social a crianças e adolescentes vítimas de violência, abuso e exploração sexual e suas famílias: referências para a atuação do psicólogo. Brasília, DF: CFP, 2009.

CONSELHO FEDERAL DE PSICOLOGIA. Conselho Federal de Psicologia e a prática da escuta especial de crianças e adolescentes vítimas de violência, abuso ou exploração sexual. Brasília, DF: CFP, 2015. Disponível em: https://bit.ly/3hJJKm2. Acesso em: 12 out. 2019.

FELIPE, J. Afinal quem é mesmo o pedófilo? Cadernos Pagu, Campinas, n. 26, p. 201-223, 2006.

NATHAN, Tobie. Há algo de podre no reino de Édipo. In. GABEL, Marceline (Coord.). Crianças vítimas de abuso sexual. Grupo Editorial Summus, 1997. p. 15-28.

NEVES, A. S. et al. Abuso sexual contra a criança e o adolescente: reflexões interdisciplinares. Temas em Psicologia, Ribeirão Preto, v. 18, n. 1, p. 99-111, 2010. 
ORGANIZAÇÃO MUNDIAL DA SAÚDE. CID-10: Classificação Estatística Internacional de Doenças e Problemas Relacionados à Saúde. 10. ed. rev. São Paulo: Edusp; 1997. 3 v.

RIOS, L. F. Parcerias e práticas sexuais de jovens homossexuais no Rio de Janeiro. Cadernos de Saúde Pública, Rio de Janeiro, v. 19, n. 2, p. 223-232, 2003.

SAFFIOTI, H. I. B. Violência doméstica ou a lógica do galinheiro. In: KUPSTAS, M. (org.). Violência em Debate. São Paulo: Moderna, 1997. p. 39-57.

SANTOS, S. S.; DELL’AGLIO, D. D. Quando o silêncio é rompido: o processo de revelação e notificação de abuso sexual infantil. Psicologia \& Sociedade, Florianópolis, v. 22, n. 2, p. 328-335, 2010.

SCHREINER, M. T. O abuso sexual numa perspectiva de gênero: o processo de responsabilização da vítima. In: SEMINÁRIO INTERNACIONAL FAZENDO GÊNERO, 8., 2008, Florianópolis. Anais [...]. Florianópolis: Universidade Federal de Santa Catarina, 2008.

SERAFIM, A. P. et al. Dados demográficos, psicológicos e comportamentais de crianças e adolescentes vítimas de abuso sexual. Revista de Psiquiatria Clínica, São Paulo, v. 38, n. 4, p. 143-147, 2011. 